\title{
Research on the Social Financing Method of college sports Based on Multivariate Optimization Mathematical Model and BOT Financing Mode
}

\author{
Tingjia $\mathrm{Hu}$ \\ School of Physical Education, Jiujiang University, Jiujiang, China \\ hu_tingjia@126.com
}

Keywords: college stadium; social financing; methods; multivariate optimization

\begin{abstract}
Along with the higher education modernization ceaselessly deepen, the construction of college stadium has rapidly developed. How to make the college modern stadium be scientific managed, operated, optimum used, and benefit maximized, it is the current urgent problems to be solved for the college stadium operation. Based on the present situation of college stadium social financing, it summed up the social financing methods and strategies for college stadium operation. On one hand, it uses the mathematical model thought to make multivariate optimization analysis for college stadium social financing. On the other hand, it deepen the college stadium to open to the society. So as to, it can provide certain theory basis and implementation way for promoting the utilization of college stadium to develop in the direction of being healthy, stable and sustainable.
\end{abstract}

\section{Introduction}

With the social economic developed, education modernization steps gradually accelerates. After China hosted the 2008 Olympic Games, the construction of stadium appears a rapid development trend[1]. Across the country, there are springing up the phenomenon of the stadium constant construction. How to make good use of the modern stadium, it is the current hot topic. On the current, in this research fields ,there are also some scholars put forward their own views. Such as ,LengYinghui---the think of college stadium paid opening to the society, it uses the literature search, case investigation, expert interviews and other methods to make analysis for the feasibility and current situation of college stadium paid opening to the society[2].It puts forward constructive suggestion for the college stadium open situation. And it puts forward the college stadium's financing, but the overall effect is not strong. JingZhaoli--- institution of higher education sports facilities market operation study that taking shandong province for example. It mainly carry on the investigation on 18 universities' sports facilities operating condition and the sports facilities operating status in shandong province. It uses the method of combining quantitative and qualitative to research[3]. At last ,it obtains a result that there is a tremendous potential of sports facilities construction in shandong province . But there are so many reason limiting the development of college stadium.HuangYao, GuanQingpei--- using the BOT mode to have a feasibility study on university's sports facilities construction. It mainly summarized the construction of sports facilities by using the BOT financing mode. And at the same time, it demonstrated the feasibility of college stadium using BOT financing mode. Finally, it designs the college stadium's construction projects using the BOT mode. It concluded that it is feasible to the construction of college stadium by using BOT financing mode[4].And it further analyzes the BOT financing to construct college stadium project's specific implementation process. WangJin---Trying to talk about the PPP financing model in our country financing's application. It mainly use the literature material method and logic analysis method. It aims at our country stadium present financing problems to introduce and apply the PPP financing model theory. In the whole research process, it expound that China sports industry is facing an important development opportunities and challenges. ZhangMingquan---the feasibility analyses on college stadium diversified financing .In the perspective of the sports industry marketization and socialization, this paper analyzes the feasibility of diversified financing for ordinary college stadium[5].It provide feasibility reference to promote the establishment of college stadium diversified financing system. 


\section{The social financing mode analysis of the current major stadium}

A. College stadium's paid open to the society

College stadium who guarantees themself on the basis of normal sports teaching, sports training, make the business development of stadium in domestic or foreign. During the time of the good service in school, it should do well for the social service. Namely, when it provides sports sites for the school teachers and students, at the same time, it should solve the shortage of social stadium problem .College stadium becomes the link between college and social connection, sets up the school's good social image. Besides, it increases the college stadium's operation efficiency, and improves the utilization ratio of college stadium.

B. The application of PPP financing model in stadium financing

The stadium social financing is the focus of the topic. In foreign country, a lot of stadiums social financing model have been applied to the practice. Such as ,in America, a lot of stadium use PPP (Public - Private - Partnership) mode[6]. The main model is the Public - Private - cooperation. The Concrete model is as below.

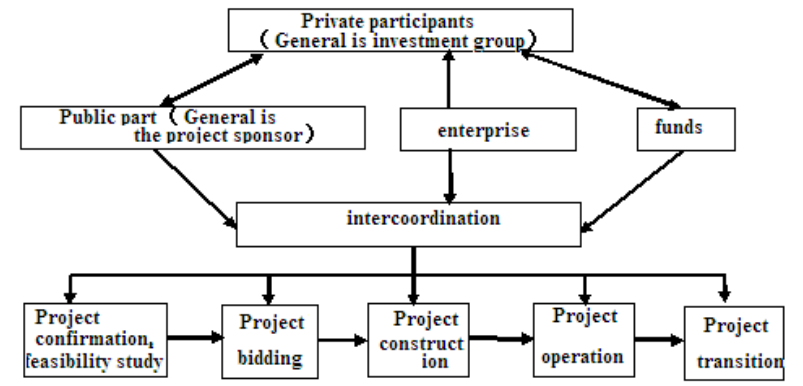

Figure 1. The application model of PPP financing model in stadium financing

As shown in Figure 1, the application of PPP financing model in stadium financing integrates the private, public with cooperation, the three joints.It coordinates with each other and uses funds. In the actual operation process , among the three factors which are selected for public or private departments to provide public service.Then it establishes a long-term cooperation relations. the relationship is generally based on the contract or agreement, so as to share the benefits and risks. Through the cooperation between the three factors, it will constitute the competition relationship[7]. Thus it will take the advantages on mode operation. In the actual operation process, the risk of the change model social financing investment could be far less than the traditional social financing. The government and relevant departments will involve in the process of stadium operation to decrease the risk .For any ambiguity, it can change the stadium operations. When there are many of the coordination, it will get the optimization operation.

C. The application of BOT financing mode in stadium financing

BOT financing mode mainly refers to " construct - operation- transfer". In China, the project is also known as the franchise business mode. The government organization is the main body. Through the construction project to recruit quotient to part of the group, build stadium and operate. In accordance with the agreement of the relevant government departments, some business enterprise is responsible for the construction operation, profit and risk, profit and loss. After the agreement period, the project ownership belongs to the state or related departments. The application of BOT financing mode in college stadium financing whose concrete process is as below.

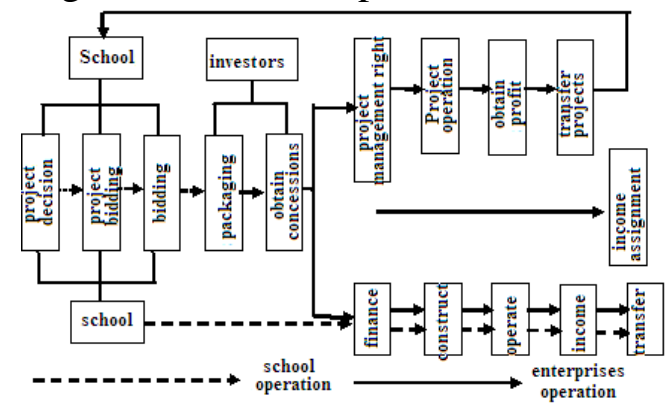

Figure 2. The application process of BOT financing mode in college stadium financing 
As shown in Figure 2, the application of BOT financing mode in college stadium financing refers to the mutual investment construction by combining schools' using the land right form with the enterprise.

\section{The multivariate optimization analysis of college stadium social financing mode}

The diversification of college stadium social financing mode

In the research of college stadium social financing mode ,it should consider the existence of the multivariate optimization. In the establishment of college stadium's ownership , at the same time, it should be adhere to the investment and profit coordination principle. It takes the staff capital raising, introduces investment, and joints enterprise measures to increase the new facilities .So as to fill the blank of college financing, improve the optimization index of college stadium social financing mode, give full play to the college sports facilities' resources advantage. Such as n kinds of financing way, $\mathrm{m}$ kinds of mode, some of the financing way satisfy the school internal demand. It also have some parts meet the requirement of the society. Assuming that each kind of financing way has stable conditions[8] : $a_{i j}(i, j=1 \ldots n), h_{i j}(i=1 \ldots m ; j=1 \ldots n)$.Its financing way, respectively, is the $\mathrm{j}$ way which need to meet the $\boldsymbol{i}$ kind of school internal demand. The i kind of social demand index, which says the school internal demand, social demand direct consumption coefficient, are constants. And there is no matter with the product yield . $X=\left(x_{1}, x_{2}, \ldots, x_{n}\right) 、 Y=\left(y_{1}, y_{2}, \ldots, y_{n}\right)^{T}$ 、 $U=\left(u_{1}, u_{2}, \ldots, u_{n}\right)^{T} 、 Z=\left(z_{1}, z_{2}, \ldots, z_{n}\right)^{T}$ respectively shows that in a period, the amount of financing ways, the final school demand, social demand, and the direct consumption in the process of foreign business.

The optimization model of building college stadium social financing mode

If $A=\left(a_{i j}\right) m \times n, H=\left(h_{i j}\right) m \times n$,they respectively represent the matrix of school internal demand, the direct consumption in the process of foreign business. According to the model hypothesis, and it can get the mathematical model[9]:

$$
\left\{\begin{array}{l}
X=U+Y \\
U=A \cdot X \\
Z=H \cdot X
\end{array}\right.
$$

In the model ,the first equation is a balance model equation. the latter two were called intermediate (school internal demand) consumption, the original (foreign business) consumption function model. In practical applications, the variables of the model which are involved in the following relationship is linear. From the building model, it can get $X=A X+Y$.If matrix I - A is reversible (I represents $\mathrm{n}$ class unit matrix), it gets $X=(I-A)^{-1}-Y, Z=H \cdot(I-A)^{-1}-Y$.it considered the school internal demand consumption.After a enterprise receives the $\mathrm{Y}$ school internal demand, it needs to organize the actual investment and prepare foreign operation yield.

At the same time, $\left\{B^{(k)} \mid k=1,2 \ldots\right\}$ is bounded. that's to say $\forall i, j=1 \ldots n,\left\{b_{i j}^{(k)} \mid k=1,2 \ldots\right\}$ is bounded.

In the actual operation process , the college plays a supervision and management responsibility, it bears a certain risk. So its characteristic distribution can be obtained: $X>0, Y>0, A \geq 0$, and $X=A X+Y$. Therefore $0 \leq(A X=X-Y) \leq X$, namely each financing way and among the area, there are positive correlation relationship.

Considering the school internal consumption, it is available that[10]:

$0 \leq\left(A^{2} X=A(X-Y)=A X-A Y=X-Y-A Y\right) \leq X$.

According to this available method, it gets:

$0 \leq A^{k} X=X-\left(Y+A Y+A^{2} Y+\ldots+A^{k-1} Y\right) \leq X$,

That is for arbitrary $\boldsymbol{k}$, we have $\sum_{j=1}^{n} b_{i j}^{(k)} \cdot y_{j} \leq x_{i}$, so $b_{i j}^{(k)} y_{j} \leq x_{i}$.then we can detrude $b_{i j}^{(k)} \leq x_{i} / y_{j}$,so that $\left\{b_{i j}^{(k)}\right\}_{k=1}^{\infty}$ is bounded. Therefore, for $\left\{\boldsymbol{b}_{i j}^{(k)}\right\}_{k=1}^{\infty}$, when it is $\boldsymbol{k} \rightarrow \infty$, it has astringency. That is 
to say that $\lim _{k \rightarrow \infty}\left(B^{(k)}=\sum_{i=1}^{k} A^{i}\right)$ has astringency. So we can record it as $B=\left(b_{i j}\right)_{n \times n}=\lim _{k \rightarrow \infty}\left(B^{(k)}=\sum_{i=1}^{k} A^{i}\right)$, it it the optimization model of college stadium social financing mode .

\section{The empirical analysis of multivariate optimization model for college stadium social financing mode}

On the multivariate optimization mode of college stadium social financing mode , the entire college need to evaluate the whole project . The specific process is as below.

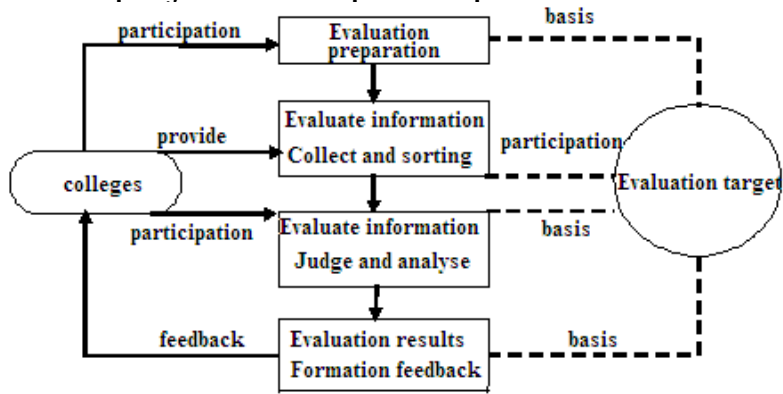

Figure 3. The multivariate optimization feedback model of college stadium social financing mode

As shown in Figure 3, college stadium's social financing multivariate optimization feedback model .Through the interaction with the enterprise, it is on the basis of the college stadium's multivariate optimization model of social financing mode. First of all, it begins with the evaluation preparation. Secondly, it carries on the evaluation of information collection and sorting, on the basis of the organization of enterprise participating in bidding mark. According to the evaluation target to make judgment analysis of evaluation information. Finally, it forms the evaluation result feedback[10]. The following is a simple college stadium social financing input-output table (social operation part slightly), it is the application basis of input-output analysis model:

TABLE I. THE COLLEGE STADIUM SOCIAL FINANCING INPUT-OUTPUT TABLE

\begin{tabular}{|c|c|c|c|c|c|c|c|c|}
\hline & \multicolumn{5}{|c|}{ Intermediate production } & \multirow{2}{*}{$\begin{array}{c}\text { Final } \\
\text { output }\end{array}$} & \multirow{2}{*}{$\begin{array}{c}\text { Total } \\
\text { output }\end{array}$} \\
\hline & & 1 & 2 & $\cdots$ & $n$ & Total & & \\
\hline \multirow{4}{*}{$\begin{array}{c}\text { Inter } \\
\text { medi } \\
\text { ate } \\
\text { input }\end{array}$} & 1 & $X_{11}$ & $X_{12}$ & $\cdots$ & $X_{1 n}$ & $u_{1}$ & $y_{1}$ & $X_{1}$ \\
\hline & 2 & $X_{21}$ & $X_{22}$ & $\cdots$ & $X_{2 n}$ & $u_{2}$ & $y_{2}$ & $X_{2}$ \\
\hline & $\cdots$ & $\cdots$ & $\cdots$ & $\cdots$ & $\cdots$ & $\cdots$ & $\cdots$ & $\cdots$ \\
\hline & $\mathrm{n}$ & $X_{n 1}$ & $X_{n 2}$ & $\cdots$ & $X_{n n}$ & $u_{n}$ & $y_{n}$ & $x_{n}$ \\
\hline
\end{tabular}

As is shown in Table 1, assuming that a college stadium's construction has $n$ kinds of facilities. The $n$ kind of facilities are recorded as one of the profit project of stadium's operation . The inputoutput table reflects the construction of the stadium in a production cycle of the statistical results: $x_{i j}(i=1, \ldots, n ; j=1, \ldots, n)$ shows the $\mathrm{i}$ kind of facilities of the $\mathrm{j}$ facilities as earnings management consumed yield. $u_{i}=\sum_{j=1}^{n} x_{i j}$ shows the i kind of facilities college consumed yield in this period. $y_{i}$ shows the number of foreign operation. $x_{i}=u_{i}+y_{i}$ shows the $\mathrm{i}$ kind of operation project gross income. $a_{i j}=x_{i j} / x_{j}$ means the $\mathrm{j}$ kind of projects consume business income. Namely, it is the direct consumption coefficient. The direct consumption coefficients matrix $A=\left(a_{i j}\right)_{n \times n}$ reflects a enterprise operation benefit. Considering the college stadium internal consumption function model $U$ $=\mathrm{AX}$, obviously, it can get input limit $\mathrm{U}$. the enterprise must firstly invest $A U=A^{2} X$, which is called the the secondary indirect consumption vector of operation requirements. And at the same time, there are the the triple indirect consumption vector of operation requirements $A^{3} U$, the quartic indirect consumption... , it is available[11,12]:

$A X+A^{2} X+A^{3} X+A^{4} X+\ldots=\left(A+A^{2}+A^{3}+A^{4}+\ldots\right) X$ 
According to the infinite type convergence of college stadium social financing multivariate optimization model, but it isn't a component of the vector which tends to infinity. The whole financing tends to be optimized, so the college stadium social financing is becoming more meaningful.

\section{Conclusion}

How to make a scientific management operation for the modern college stadium is one of the urgent resolved problems. Colleges need to gradually seek for financing breakthrough in physical education reform. It should have under the current conditions, a scientific and reasonable arrangement for the allocation of resources of college stadium. Then it can play a better social benefits and economic benefits.

\section{References}

[1] Yinghui Leng. The think of college stadium paid opening to the society. The Shanghai sports institute journal, 2005, 29 (6):78-81.

[2] ZhaoLi Jing.The operation study on higher education sports facilities marketed ---taking shandong province for example . Shandong agricultural university, 2011.

[3] Yao Huang, Qingpei Guan. The feasibility study on college sports facilities construction by using the BOT mode. Journal of shandong university of science and technology (social science edition), 2009 (6):134-137.

[4] Jin Wang. Try to talk about the PPP financing model in our stadium financing's application . Journal of hebei institute of physical education, 2009(3):109-112..

[5] Mingquan Zhang. College stadium diversified financing feasibility analyses.Times education (education teaching edition) ,2010 (10):77-81.

[6] Lujun Li,Hongyuan Fu.China's public stadium BOT project financing mode study. Hubei sports science and technology ,2006 (09):34-37.

[7] Li Lei .The research of Beijing college stadium's resource utilization and influence factors. Beijing sports university journal ,2011 (3):96-98.

[8] Jia Liu,Pulin Luo. Colleges' stadium management status and management countermeasures exploration.Neijiang technology ,2011 (8):78-83.

[9] Yong Liu, Mingming Liu, Yan Shi. The long-term mechanism research of the serving to the society for our country school stadium.Tianjin sports college journal ,2010 (1):8-9.

[10] Luea Rebeggian. Pulic VS.Private Spending for Sports Facillties - The Case of Germany2006.Public Finance and Management.Volume Six,Number3,PP.395- 435,2006.

[11] Mcnatt Robet. The Big Apples Other Dream Project. BUSINESS WEEK, 2003,(03):1125-1132.

[12] Charles Santo.The Eeonomic Impact of Sports Stadiums:Recasting the Analysis in Context.Journal ofUrban Affairs,Volume27,Number2,Pages177-191.2005. 